\title{
Musings on MOOCs
}

MOOCs (massive open online courses) are causing a revolution in higher education today. What will be the impact of this revolution on mathematics teaching in colleges and universities? The Notices is hosting a discussion of MOOCs, which began in the November 2013 issue with the Opinion column "MOOCs and the future of mathematics" by Robert Ghrist of the University of Pennsylvania. The following three articles continue the discussion. With the aim of continuing the discussion over the coming several months, the Notices invites readers to submit short pieces (eight hundred words or less) on the subject of MOOCs in mathematics. Please send contributions to notices-mooc@ams.org.

\section{Petra Bonfert-Taylor}

When I was invited to teach a MOOC through Wesleyan's contract with Coursera, I was excited because I love exploring technology. But my excitement was soon mixed with questions. Although I have been enthusiastically experimenting with technologically driven curricular pedagogies such as flipped classrooms and blended learning, this was to be a whole different order of public endeavor. Also, for the first time in my experience as a faculty member, I felt that the foundations on which I construct my classes were in question. Is the MOOC model educationally effective, or, more accurately, for which cohort of students is the model effective? Will MOOCs, or their evolutionary spawn, destroy the time-tested and successful educational model in which we work (and believe)? More prosaically, if I agree to teach a MOOC, what should it be about and how would I construct it?

I claim no special creative insight into the problems and opportunities that MOOCs present: indeed, each of the above thoughts, and much, much more, have been hashed over ad infinitum in essays, blogs, papers, and over numerous cups of coffee in department lounges. I find that opinions are strong and firmly held, but it is unfortunate that the amount of practical hands-on experience that informs many of these opinions is so slight. I quickly became fascinated at the possibility of discovering for myself something of the potential of MOOCs through the actual experience of producing a MOOC, and for me that was the decisive motivation for going forward.

Petra Bonfert-Taylor is professor of mathematics at Wesleyan University. Her email address is pbonfert@wes leyan .edu. DOI: http://dx.doi.org/10.1090/noti1074
We are, regardless of the ultimate fate of MOOCs, at a moment where hands-on engagement, experimentation, and assessment are required of the professoriate. A central tenet of the Academy is that knowledge should be both free and accessible and that it should be diffused widely. Whether or not MOOCs can or should replace the more traditional modes of teaching has come to be nearly moot in my mind: it is clear that MOOCs have a fabulous potential for providing a platform to spread knowledge widely and inexpensively.

My MOOC, "Analysis of a Complex Kind", has an ambitious goal to take students from the beginnings of complex numbers, via important concepts such as Cauchy theory and an excursion to fractals, all the way to the Riemann Hypothesis and its relation to prime numbers. Squeezed into six weeks, the course cannot offer full rigor 100 percent of the time. My goal in this course is not to simply fill a bucket with knowledge, but also to spark a lasting interest and curiosity in a beautiful corner of mathematics. We can easily make the argument that a greater appreciation for mathematics would have many positive and practical outcomes for K12 education in the United States, for the economy, for political decision making, etc. Easy access to compelling presentations of mathematics can only help.

Now, a course on complex analysis won't be the one that convinces vast numbers of people of the beauty and utility of mathematics, but I have hopes that it's one (of many) steps in the right direction. It would be selfish, however, to insist that the major impact of MOOCs be felt mainly at our own front door. Statistics show, for example, that Coursera students come from 195 nations, with forty percent living in the developing world. MOOCs have a tremendous potential to provide a service to people around the globe.

I will end on a practical note. Preparing my MOOC has been an all-encompassing adventure. Since the course does not follow a typical undergraduate class on complex analysis, I had to develop the curriculum, write all of the lectures, typeset all of the lectures (this is the part you don't have to do when lecturing with chalk), record, and finally edit the lectures. I was fortunate in that I already had some recording experience from previous experiments with flipped classrooms and blended learning; nonetheless, hundreds of hours went into this process. Next was the creation of in-video 
quizzes that help students remain engaged with the material and check in with their understanding, and finally, weekly homework assignments and exams. It was a lot of work, and I was continually questioning the tradeoffs I was incurring for doing this. The extra amount of work, in addition to my regular faculty, research, and teaching duties, is overwhelming at times. On one of those days when I felt this acutely I received an email from a prospective student in South Africa. In it, the student wrote: "I can't begin to express just how much it means to me (and to others like me, I'm sure) that people such as yourself are willing to put in so much effort to enable people who haven't got the opportunity to really pursue a mathematics education properly. I look forward to the day, hopefully in the near future, when one will be able to get an, at least approximate, education in maths online as you would if you attended a full time university."

I was moved and humbled by this email. It reminded me of all of the advantages I have had throughout my life and career, advantages in part due to happy accidents such as when, where, and to whom I was born, and the opportunities that were right on my doorstep for the taking. In short, the knowledge on which my career was based was easily accessible to me. Also, it reminded me of how very fortunate I am to be given the opportunity to reach out to people all over the world and offer to them a small portion of a beautiful topic in mathematics-for free.

\section{David M. Bressoud}

MOOCs are not the issue. They are simply one manifestation of the proliferation of web-based resources that range from complete lectures to demonstration videos to Q\&A sites to online homework. The real issue is how the availability of all of these facilities will affect the future of mathematics and its instruction.

These tools can be enormously freeing. When I do not have to grade routine homework or work through multiple examples of a particular technique, I can make better use of my time with my students to probe their understanding and focus on their questions and difficulties.

MOOCs will be most useful when they provide a range of carefully vetted and coherent materials from which faculty can pick and choose. We are already at the point where a faculty member can say, "After I have introduced the next topic to you in class, watch this lecture, online. Read this material, online or in print. Try these problems, online. Come to class where I will help you through

David M. Bressoud is the DeWitt Wallace Professor of Mathematics at Macalester College. His email address is bressoud@macalester. edu. the difficulties you have encountered. Before moving on, check your understanding against these problems, online. See if you can draw from all we have learned to tackle this challenging problem, presented online. Get feedback on your ideas and attempts from your peers, online. Come to class where you will talk through your solution and the entire class will critique it." This approach to education-the instructor managing a rich and immersive experience for the students-is still unusual. I believe that the day is coming when it will be expected. As the future will demand more of teachers, so teachers will be unable to meet these expectations without the aid of web-based resources.

The appeal of this scenario is that it concentrates the human component of education on what humans are best at: drawing on one's own experience to recognize the difficulties that others are encountering and tailoring guidance to help each individual progress. There may come a time when computers can emulate all of the complexities of human interactions of which we are capable. We are still a long way from that day. However, the availability of such web-based agents does mean that there is less need for impersonal instruction delivered by live people. The business model that has supported so many departments of mathematics-a large research faculty with low teaching responsibilities supported by meeting large numbers of students in settings that require minimal interaction-will no longer be sustainable.

There is one other observation I wish to make. Ghrist ["MOOCs and the future of mathematics", Notices, November 2013] points out that low-cost platforms can liberate us from the publishing bureaucracy. The problem is that few of us will have the time to develop our own materials, and anyone who searches for such resources online is quickly inundated with options. In an era of overwhelming choices, it is the reputable bundlers who will dominate. MOOCs will continue to play a role in satisfying the needs of the curious and the highly self-motivated, especially those without access to particular courses, but they will be most useful as bundles of high-quality coordinated tools. If they are ever to be self-supporting, this is what will fund them. The big publishers understand this. They no longer produce just fat, full-color books. Big publishers now assemble multifaceted packages that do everything from keeping track of grades to providing videos by leading educators. They know that what sells such packages is their usefulness to the human instructor. This is the direction in which MOOCs will need to evolve. 


\section{Harvey Diamond}

Math is hard. It's labor intensive. It requires engagement. The ideas are important. The symbology we use to express those ideas is dense and abstract and takes getting used to. That's why every mathematics text advises the reader, if they want to learn, to grab paper and pencil. And it's why graduate students stay up till the wee hours discussing mathematics with each other. The public knows math is hard, though it has only a hazy view of why. And the public is tired of math being hard. College administrators are tired of math being hard. We've gotten the message: You will teach them what they need to know. We'll give you just these resources and you'll get it done.

And now we're tired of math being hard.

Class sizes have crept up, or exploded in some cases. Administrators understand $1,2,3, \ldots, n$, and after you've got 50 students, why not 100 , or 300 , or 1,000 , or 10,000 . Large sections, or large multisection courses, are now managed as much as taught, with uniform pacing, monitored attendance, the handouts handed out, the worksheets worked, the computer assignments clicked through, the sample problems reviewed, and no one reads the textbook anymore. No one has to. Exams are circumscribed by questions the students have already practiced; they think that's only fair-that's how it's always been for them. The exams are graded by teams of harried GTAs and adjuncts, or they're multiple choice and computer graded. Post the grades, compute the averages and distribution, write it all up for your teaching portfolio or for the annual report to the dean. See, math really isn't that hard; it just has to be managed and then assessed. To be sure, this view is something of an exaggeration and overly broad. It does not recognize the many individuals positively affecting outcomes, making extensive and innovative efforts to make this system work as well as it can. But the gradient is clearly uphill, and the negative trends are unmistakable.

Into that environment come the MOOCs. I don't mean the MOOC model per se, but rather the idea of learning organized around a comprehensive suite of online materials. Instead of a lecture in a classroom with 50 students, or 300 students, with students copying notes in silence, we have, say, an online video, carefully produced by experts in the field, featuring the best teachers, that can be stopped and reviewed, at any time, at any place, even on your phone. Instead of handouts there are links to online textbooks, supplementary information, deeper analysis and discussion, applications to physical situations, dynamically worked

Harvey Diamond is professor of mathematics at West Virginia University. His email address is diamond@math.wvu. edu. out example problems with commentary, little questions that help you know if you understood the material, challenging questions, and you can take as much time as you need. You can watch it with friends, with group mentoring, with online queries possible, with teaching assistants, with a professor. Anything is possible. Before, you could get away with memorizing problem templates. Now you can be guided and prodded into listening and understanding and articulating because there are unlimited resources and plenty of time-your time instead of limited class time. So, why would all this not be an improvement if done well? Why could this not bring about not just savings in personnel costs and instructional time, but a return to deeper learning, more intellectually accessible, and more widely available, than ever before?

Of course we know what's missing: human feedback, the judgment of written work, which is of particular importance in mathematics, perhaps the necessary discipline of having to be somewhere at a certain time, the sharing of ideas. But there is no reason all that cannot be supplied. If we don't do it, you might find commercial tutoring firms (Kaplan, Princeton Review, etc.) moving in to play such assistive roles. There are many positive possibilities for education here and an ability to accommodate a wide range of student backgrounds, abilities, and learning preferences.

So bring it on, but do it right. There are people and technology companies behind these recent efforts who know how to get things done and who know quality.

There is not space here for other important issues: Making sure that standards are maintained in content and testing; how credit will be granted and recognized; what the longer term effect will be on colleges and universities and our entire higher education system; and, for us in particular, what the mathematics faculty will look like in ten or twenty years if universities start to think they can get along without us.

I must briefly address one more issue: using MOOC platforms in K-12 education. If we're going to open the knowledge of mathematics to everyone in the world, how about teachers and children, who labor with textbooks and materials of limited quality and depth? There are laudable learning aids online, such as Khan Academy, but why not a comprehensive curriculum? A relatively small investment by the National Science Foundation or the Department of Education or even private philanthropy could get that set up, free for any student or school system to use. Think what that might do to open up opportunity to everyone. 